\title{
Detailed Model of the Peroxidase-Catalyzed Oxidation of Indole-3-Acetic Acid at Neutral pH
}

\author{
Sergey N. Krylov* and H. Brian Dunford* \\ Department of Chemistry, University of Alberta, Edmonton, Alberta, Canada T6G $2 G 2$
}

Received: August 2, 1995; In Final Form: September 20, $1995^{\otimes}$

\begin{abstract}
A mechanistic model of peroxidase-catalyzed oxidation of indole-3-acetic acid (IAA) at neutral $\mathrm{pH}$ has been developed, characterized, and compared with experiments. The model is based on experimental facts showing that IAA is oxidized in the presence of HRP by two pathways: (i) the standard peroxidase cycle, which is accompanied by (ii) a nonenzymatic free radical chain reaction. The peroxidase cycle normally requires the addition of a hydroperoxide, whereas IAA oxidation does not. Therefore, the model includes the enzymatic peroxidase cycle which is initiated by organic hydroperoxide (ROOH) derived from autoxidation of IAA. It also includes a nonenzymatic free radical chain which utilizes oxygen, oxidizes IAA, and recycles ROOH required for the enzymatic cycle. Available experimental values of rate constants were used. Unavailable rate constants were initially estimated analytically using the steady state assumption and then optimized by computer simulation. There is a unique set of rate constants which satisfies the model. The average deviation of simulated kinetic traces from experimental ones was less than 5\%. Critical values of the rate constants were determined; for values smaller than the critical values IAA oxidation stops. In the pre-steady state the concentration of ROOH rises exponentially. Thus, a decrease of the initial concentration of ROOH by 3 orders of magnitude gives rise to only a 1 min delay of reaction. For all intermediates except ROOH the steady state was reached in $1 \mathrm{~min}$; for $\mathrm{ROOH}, 10 \mathrm{~min}$ after reaction initiation. More than half of the oxidation of IAA occurs by the chain reaction, a nonenzymatic pathway. The model satisfactorily describes all available experimental kinetic data and predicts some previously unobserved behavior which should stimulate further experiments.
\end{abstract}

\section{Introduction}

It is known that peroxidases are able to oxidize several substrates aerobically without added peroxide. Among these substrates are indole-3-acetic acid (IAA), ${ }^{1-5} \mathrm{NADH},{ }^{6}$ dihydroxyfumarate, ${ }^{7}$ and isobuteraldehyde. ${ }^{8}$ Peroxidases utilize oxygen in these reactions. Therefore, such processes are called peroxidase-oxidase reactions. They are of interest for researchers because (i) they exhibit a number of nonlinear dynamic behaviors such as bistabilities and oscillations, ${ }^{6-9}$ (ii) they produce chemiluminescence, ${ }^{8,10-12}$ and (iii) at least one of them (oxidation of IAA) is an important physiological reaction. ${ }^{13}$ IAA is a known phytohormone. The peroxidase-catalyzed oxidation of IAA plays an important role in IAA catabolism in vivo and thus in regulation of plant growth at the molecular level. ${ }^{13}$

IAA oxidation is a complex process in which many reaction intermediates and final products are formed. ${ }^{14}$ Moreover, peroxidase is converted from the native enzyme into several catalytic and inactive forms. ${ }^{2-5,15,16}$

Two main reaction pathways have been recognized, labeled peroxidase and oxidase. In the classical peroxidase pathway, hydroperoxide $(\mathrm{ROOH})$ is the substrate of native enzyme. IAA is the substrate for the enzyme intermediates, HRP-I and HRPII. $\mathrm{ROOH}$ is recycled in a free radical chain reaction. ${ }^{2,3,5}$ The oxidase pathway involves the ferrous enzyme and HRP-III. The substrate of $\mathrm{Fe}^{2+}-\mathrm{HRP}$ is oxygen, and the substrate of HRPIII is IAA. ${ }^{3,4}$ The pathway which is followed depends upon the experimental conditions. A high $\mathrm{pH}$ promotes the peroxidase pathway, while a low $\mathrm{pH}$ favors the oxidase pathway. ${ }^{3-5}$

* To whom correspondence may be addressed. For S.N.K.: phone, (403) 492-3772; fax, (403) 492-8231; e-mail, skrylov@ gpu.srv.ualberta.ca. For H.B.D: phone, (403) 492-3818; fax, (403) 492-8231; e-mail, brian.dunford@ualberta.ca.

${ }^{\otimes}$ Abstract published in Advance ACS Abstracts, December 1, 1995.
Extensive studies on IAA oxidation for almost 40 years have led to an accumulation of experimental data. However, contradictions in experimental results and their interpretations abound. Some proposals are still speculative, and several questions remain unanswered. Among the unanswered questions are the following: the mechanism of reaction initiation and P-670 formation ${ }^{5,15-17}$ as well as the mechanisms of reaction inhibition and activation by the donors of electrons. ${ }^{12,18}$

In our previous work we conducted a kinetic study of the aerobic peroxidase-catalyzed oxidation of IAA at neutral $\mathrm{pH}$ without added $\mathrm{H}_{2} \mathrm{O}_{2}{ }^{5}$ The kinetic traces of IAA oxidation, HRP-II formation and disappearance, P-670 formation, and oxygen consumption were measured. It was shown that IAA is oxidized through the peroxidase pathway which is accompanied by a free radical chain reaction that recycles $\mathrm{ROOH}$. Several rate constants were determined for the first time. The data obtained allow us to develop a detailed mechanism of IAA oxidation.

Modeling is a powerful instrument for investigation of the reaction mechanism. After a hypothesis of the reaction mechanism has been developed, modeling can be used to check the hypothesis, to determine otherwise unavailabe rate constants, and to predict system behavior under new experimental conditions. Kinetic modeling has been applied to the NADH/HRP/ $\mathrm{O}_{2}$ system. $^{6,19}$ However, it had not previously been used to investigate the IAA/HRP/O $/ \mathrm{O}_{2}$ reaction.

Here we present detailed kinetic modeling of the peroxidasecatalyzed IAA oxidation using analytical and numerical approaches. The main goals were to check the validity of the suggested mechanism of IAA oxidation (the peroxidase pathway accompanied by a free radical chain reaction), ${ }^{5}$ to determine 
unavailable rate constants, and to determine the behavior of reaction intermediates predicted by the model. Of particular interest was to model the initiation step of the reaction to determine whether reaction initiation involves the oxidase pathway.

\section{Procedures}

2.1. Experimental Kinetic Traces. In our previous paper we measured the kinetic traces of HRP-II, P-670, and IAA spectrophotometrically and of $\mathrm{O}_{2}$ with an oxygen electrode. ${ }^{5}$ Here we have converted the absorbance traces of HRP-II at 430 $\mathrm{nm}$ and P-670 at $670 \mathrm{~nm}$ to the corresponding concentration traces using known extinction coefficients: $\epsilon_{430}^{\mathrm{HRP}-\mathrm{II}}=7.5 \times 10^{4}$ and $\epsilon_{670}^{\mathrm{P}-670}=2.4 \times 10^{4} \mathrm{M}^{-1} \mathrm{~cm}^{-1}$. ${ }^{-}$The absorbance of IAA at $290 \mathrm{~nm}$ was converted to concentrations using the expression

$$
[\mathrm{IAA}]^{t}=\frac{\left(A^{\infty}-A^{t}\right)}{\left(A^{\infty}-A^{t_{0}}\right)}[\mathrm{IAA}]^{t_{0}}
$$

where $A^{t_{0}}, A^{t}$, and $A^{\infty}$ are absorbances at zero time, at time $t$, and when the asymptopic value of the single-exponential curve is attained. ${ }^{5}$ The oxygen kinetic trace, which was measured in arbitrary units, was converted to concentration as a function of time using the initial concentration of oxygen in the reaction mixture, $2.5 \times 10^{-4} \mathrm{M}^{20}$

All calculated kinetic traces consisted of $N=151$ points with time intervals of $40 \mathrm{~s}$. They were placed in an ASCII file available for reading by programs integrating the reaction rate equations (see section 2.3 below).

The average HRP-II concentration in the steady state of the reaction was calculated according to

$$
[\text { HRP-II }]_{\mathrm{av}}=\frac{1}{t_{2}-t_{1}} \int_{t_{1}}^{t_{2}}[\mathrm{HRP}-\mathrm{II}]^{t} \mathrm{~d} t
$$

where $t_{1}=2 \mathrm{~min}$ and $t_{2}=64 \mathrm{~min}$ are the time of the beginning and the end of the steady state, and [HRP-II $]^{t}$ is the concentration of HRP-II at time $t$. The concentration of [HRP-II $]_{\mathrm{av}}$ thus calculated was $0.58 \mu \mathrm{M}$.

2.2. Algorithm for Rate Constant Determination by Computer Simulation. For rate constant determination by computer analysis we used a method of sequential optimization. The rate constants were optimized one by one in an iterative procedure using the criterion of minimum of deviation of all simulated kinetic traces from experimental ones. Deviation is defined as

$$
D=\frac{1}{M} \frac{1}{N} \sum_{j=1}^{M} \sum_{i=1}^{N}\left|C_{i j}^{\exp }-C_{i j}^{\text {sim }}\right|
$$

where $N=151$ is the number of time points on experimental kinetic traces (section 2.1), $M=4$ is the four substances for which kinetic traces were experimentally measured (HRP-II, $\mathrm{P}-670$, IAA, and $\mathrm{O}_{2}$ ), $\mathrm{C}_{i j}^{\exp }$ and $\mathrm{C}_{i j}^{\mathrm{sim}}$ are experimental and simulated concentrations of substance $j$ at time $i$. The contributions of those substances to $D$ have to have identical weights. Therefore, $\mathrm{C}_{i j}^{\exp }$ and $\mathrm{C}_{i j}^{\text {mod }}$ were normalized. The concentrations of the enzyme species HRP-II and P-670 were divided by initial enzyme concentration, $1 \mu \mathrm{M}$. The concentrations of the reactants IAA and $\mathrm{O}_{2}$ were divided by their initial concentrations, 50 and $250 \mu \mathrm{M}$, respectively.

2.3. Computer Programs. The program for calculation of all $10 \times 10$ minors for the $12 \times 10$ stoichiometric matrix was written by one author (S.N.K.) in FORTRAN using the standard routine LUDSMP for determinant calculation. ${ }^{21}$ The program input is a $12 \times 10$ stoichiometric matrix (see section 4.1 below). The program constructs $10 \times 10$ minors by deletion of two rows. The output is the matrix of minors.

The programs (FORTRAN double precision) for integration of reaction rate equations, which were designed by one author (S.N.K.), used a Runge-Kutta procedure. ${ }^{21}$ The program for the rate constant determination integrates the system of reaction rate equations and creates a temporal data file which contains times and concentrations. Since the program has adaptive stepsize control, this temporal file contains data with nonequidistant time intervals. Therefore, the program further transforms the temporal data file to a data file with equidistant time intervals, $40 \mathrm{~s}$, the same as in the experimental data file (section 2.1). Thus, deviation can be calculated using simulated and experimental data files (section 2.2). The program for visualization of the computer simulation results is quite similar to that for rate constant determination. The only difference is that the visualization program creates a final ASCII file which contains both experimental and model concentrations for equidistant time intervals of $40 \mathrm{~s}$. This file is imported into EXCEL electronic tables for graph preparation.

All the programs are available upon request.

2.4. Computing Resources. We used an IBM compatible computer with a 486 coprocessor operating at $66 \mathrm{MHz}$ for our computer analysis. Since the program integrating reaction rate equations operates in adaptive step-size control mode, the duration of calculation is strongly dependent on the rate constants. The rate equations are listed in Table 1 . In our model the time-limiting rate constant for computation is $k_{6}=2.0 \times$ $10^{8} \mathrm{M}^{-1} \mathrm{~s}^{-1} .22$ For this value of $k_{6}$ and zero step-size limit (highest level of integration precision) the calculation of 100 min of numerical data takes about $700 \mathrm{~min}$ of computer time, while for $k_{6}=1.0 \times 10^{6} \mathrm{M}^{-1} \mathrm{~s}^{-1}$ only about $3 \mathrm{~min}$. It was found that $k_{6}$ did not influence the result of simulation if $k_{6} \gg$ $k_{3}$ and $k_{6} / k_{8}=$ const. The reaction $\mathrm{R}_{3}$ with corresponding rate constant $k_{3}$ is the kinetic rate-limiting step (Table 1). Therefore, we used the values $k_{6}=1.0 \times 10^{6} \mathrm{M}^{-1} \mathrm{~s}^{-1}$ (which is much more than $\left.k_{3}=2.05 \times 10^{2} \mathrm{M}^{-1} \mathrm{~s}^{-1}\right)$ and $k_{6} / k_{8}=1.36 \mathrm{~s}^{-1}$ for the determination of rate constants that required 400 passes of 100 min kinetics (Figure 3). All of the other results did not require so many passes and were calculated using $k_{6}=2.0 \times$ $10^{8} \mathrm{M}^{-1} \mathrm{~s}^{-1}$.

\section{Model Development}

The main principle in development of the model was to use a minimum of species and known reactions to yield simulated data that agree with experiments. The important experimental facts are the following: at neutral $\mathrm{pH}$ the oxidation of IAA goes through the peroxidase pathway accompanied by a free radical chain reaction, oxygen is consumed during the reaction, and HRP-I apparently reacts with hydroperoxide to produce P-670, which accumulates in the reaction mixture. ${ }^{5,15}$

The reaction scheme presented in Figure 1 describes these facts. Table 1 contains relevant reaction equations and available rate constants. The reaction scheme includes the standard peroxidase cycle $\left(R_{1}-R_{3}\right)$. A unique feature of the IAA reaction is that its reduction of HRP-II $\left(R_{3}\right)$ is so slow that a second reduction of HRP-II is able to compete. Reaction $\mathrm{R}_{4}$ is the reduction of HRP-II to HRP by an unknown electron donor. For simplicity we consider this reaction to be unimolecular. The formation of P-670 is apparently initiated by the reaction of HRP-I with $\mathrm{ROOH}$, which is rate-limiting $\left(\mathrm{R}_{5}\right)^{5,15}$ Therefore, we do not consider any intermediates of this branch beyond $R_{5}$. Reactions $R_{6}$ and $R_{7}$ are the free radical chain process which regenerates the free radicals $R^{\bullet}$ as well as the hydroperoxide 
ROOH required for enzymatic cycle initiation. Reactions $R_{8}$ and $\mathrm{R}_{9}$ are chain termination steps. They could be described by a quadratic equation for free radical recombination or a linear equation for free radical reaction with a nonradical species or reaction vessel wall. For simplicity we consider only linear equations, where the donors of electrons are not specified (unimolecular reactions). It will be shown later that this simplification is justified. Reaction $R_{10}$ is a unimolecular reaction for $\mathrm{ROOH}$ destruction. ${ }^{2}$

\section{Determination of Rate Constants}

4.1. Uniqueness of the $\boldsymbol{k}$ Values. The rate constants $k_{1}-$ $k_{4}, k_{6}$, and $k_{10}$ are available from the literature (Table 1). Unknown rate constants are $k_{5}, k_{7}, k_{8}$, and $k_{9}$. Is there a unique set of the unknown rate constants which satisfy the model? The question can be answered by analysis of a stoichiometric matrix. ${ }^{23}$ A unique and satisfactory set of the rate constants exists if the rank of the stoichiometric matrix is equal to the number of reactions (rate constants). If the rank of the stoicheometric matrix is less than the number of reactions, then there exists an infinite number of rate constant sets that satisfy the model.

The stoichiometric matrix for our model is

$\begin{array}{lrrrrrrrrrr} & \mathrm{R}_{1} & \mathrm{R}_{2} & \mathrm{R}_{3} & \mathrm{R}_{4} & \mathrm{R}_{5} & \mathrm{R}_{6} & \mathrm{R}_{7} & \mathrm{R}_{8} & \mathrm{R}_{9} & \mathrm{R}_{10} \\ \text { HRP } & -1 & 0 & 1 & 1 & 0 & 0 & 0 & 0 & 0 & 0 \\ \text { HRP-I } & 1 & -1 & 0 & 0 & -1 & 0 & 0 & 0 & 0 & 0 \\ \text { HRP-II } & 0 & 1 & -1 & -1 & 0 & 0 & 0 & 0 & 0 & 0 \\ \mathrm{P}-670 & 0 & 0 & 0 & 0 & 1 & 0 & 0 & 0 & 0 & 0 \\ \mathrm{RH} & 0 & -1 & -1 & 0 & 0 & 0 & -1 & 0 & 0 & 0 \\ \mathrm{R} & 0 & 1 & 1 & 0 & 0 & -1 & 1 & -1 & 0 & 0 \\ \mathrm{ROO} \cdot & 0 & 0 & 0 & 0 & 0 & 1 & -1 & 0 & -1 & 0 \\ \mathrm{ROOH} & -1 & 0 & 0 & 0 & -1 & 0 & 1 & 0 & 0 & -1 \\ \mathrm{O}_{2} & 0 & 0 & 0 & 0 & 0 & -1 & 0 & 0 & 0 & 0 \\ \mathrm{P}_{1} & 0 & 0 & 0 & 0 & 0 & 0 & 0 & 1 & 0 & 0 \\ \mathrm{P}_{2} & 0 & 0 & 0 & 0 & 0 & 0 & 0 & 0 & 1 & 0 \\ \mathrm{P}_{3} & 0 & 0 & 0 & 0 & 0 & 0 & 0 & 0 & 0 & 1\end{array}$

This is $12 \times 10$ matrix. Its maximal possible rank is 10 . $10 \times$ 10 minors were constructed by deleting two rows from the stoichiometric matrix. The following $11 \times 11$ matrix shows the values of all $10 \times 10$ minors:

HRP-I HRP-II P-670 RH R• ROO• ROOH $\mathrm{O}_{2} \quad \mathrm{P}_{1} \quad \mathrm{P}_{2} \mathrm{P}_{3}$

\begin{tabular}{|c|c|c|c|c|c|c|c|c|c|c|}
\hline HRP & 0 & 0 & 0 & -1 & 1 & 0 & 0 & 1 & 1 & 0 \\
\hline HRP-I & & 0 & 0 & 1 & -1 & 0 & 0 & -1 & -1 & 0 \\
\hline HRP-II & & & 0 & -1 & 1 & 0 & 0 & 1 & 1 & 0 \\
\hline P-670 & & & & & -1 & 0 & 0 & -1 & -1 & 0 \\
\hline RH & & & & & 0 & 0 & 0 & 0 & 0 & 0 \\
\hline $\mathrm{R}^{\bullet}$ & & & & & & 0 & 0 & 0 & 0 & 0 \\
\hline $\mathrm{ROO}^{\bullet}$ & & & & & & & 0 & 0 & 0 & 0 \\
\hline $\mathrm{ROOH}$ & & & & & & & & 0 & 0 & 0 \\
\hline $\mathrm{O}_{2}$ & & & & & & & & & 0 & 0 \\
\hline $\mathrm{P}_{1}$ & & & & & & & & & & 0 \\
\hline $\mathrm{P}_{2}$ & & & & & & & & & & \\
\hline
\end{tabular}

For example, the number -1 located at the intercept of the row HRP-II and the column RH means that the minor obtained by deletion of the rows HRP-II and RH from the stoichiometric matrix is equal to -1 .

We see in the matrix of minors that nonzero $10 \times 10$ minors exist. This means that the rank of the stoichiometric matrix is equal to 10 ; that is, the rank of the stoichiometric matrix is equal to the number of reactions. Therefore, there is a unique set of rate constants $k_{1}-k_{10}$ which satisfy our model.

Since the rank of the stoichiometric matrix is 10 , only 10 of 12 substances are independent and there are two sets of
TABLE 1: Main Reactions, and Their Corresponding Experimentally Determined Rate Constants, Which Influence the Aerobic Peroxidase-Catalyzed Oxidation of Indole-3-acetic acid without Added $\mathrm{H}_{2} \mathrm{O}_{2}{ }^{a}$

\begin{tabular}{|c|c|c|c|c|}
\hline & reaction & rate constant & $\mathrm{pH}$ & ref \\
\hline$\left(\mathrm{R}_{1}\right)$ & $\mathrm{HRP}+\mathrm{ROOH} \rightarrow \mathrm{HRP}-\mathrm{I}$ & $k_{1}=2 \times 10^{6} \mathrm{M}^{-1} \mathrm{~s}^{-1}$ & $\begin{array}{l}7.0 \\
4.4\end{array}$ & 2 \\
\hline$\left(\mathrm{R}_{2}\right)$ & HRP-I + RH $\rightarrow$ HRP-II + R• & $k_{2}=2.2 \times 10^{3} \mathrm{M}^{-1} \mathrm{~s}^{-1}$ & 7.4 & 5 \\
\hline$\left(\mathrm{R}_{3}\right)$ & $\mathrm{HRP}-\mathrm{I}+\mathrm{RH} \rightarrow \mathrm{HRP}+\mathrm{R}^{\bullet}$ & $k_{3}=2.3 \times 10^{2} \mathrm{M}^{-1} \mathrm{~s}^{-1}$ & 7.4 & 5 \\
\hline$\left(\mathrm{R}_{4}\right)$ & HRP-II $\rightarrow$ HRP & $k_{4}=3.0 \times 10^{-3} \mathrm{~s}^{-1 b}$ & 7.4 & 5 \\
\hline$\left(\mathrm{R}_{5}\right)$ & HRP-I + ROOH $\rightarrow$ P-670 & & & \\
\hline $\begin{array}{l}\left(\mathrm{R}_{6}\right) \\
\left(\mathrm{R}_{7}\right) \\
\left(\mathrm{R}_{8}\right) \\
\left(\mathrm{R}_{9}\right)\end{array}$ & $\begin{array}{l}\mathrm{R}^{\bullet}+\mathrm{O}_{2} \rightarrow \mathrm{ROO} \\
\mathrm{ROO}+\mathrm{RH} \rightarrow \mathrm{ROOH}+\mathrm{R}^{\bullet} \\
\mathrm{R}^{\bullet} \rightarrow \mathrm{P}_{1} \\
\mathrm{ROO}^{\bullet} \rightarrow \mathrm{P}_{2}\end{array}$ & $k_{6}=2 \times 10^{8} \mathrm{M}^{-1} \mathrm{~s}^{-1}$ & 3.9 & 22 \\
\hline$\left(\mathrm{R}_{10}\right)$ & $\mathrm{ROOH} \rightarrow \mathrm{P}_{3}$ & $k_{10}=1.6 \times 10^{-3} \mathrm{~s}^{-1}$ & 4.4 & 2 \\
\hline
\end{tabular}

${ }^{a}$ Blanks indicate rate constants for which no experimental values exist. ${ }^{b}$ Value of $k_{4}$ was obtained from the $y$-intercept of Figure 6 in ref 5 .
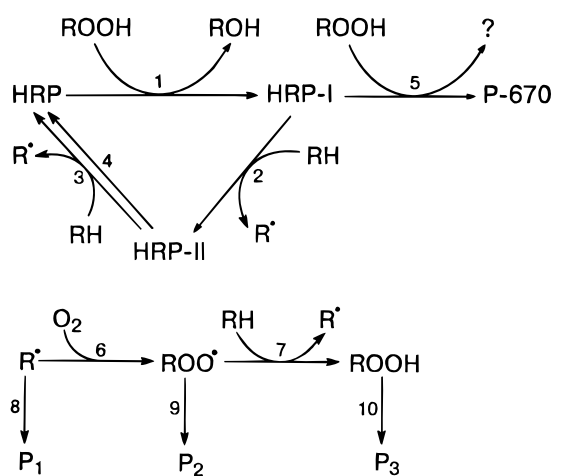

Figure 1. Model of peroxidase-catalyzed IAA oxidation at neutral $\mathrm{pH}$ : (top) enzymatic reactions; (bottom) nonenzymatic reactions.

dependent substances. The table of minors allows us to determine the two sets of dependent substances as well as the corresponding conservation relations:

$$
\begin{gathered}
{[\mathrm{HRP}]+[\mathrm{HRP}-\mathrm{I}]+[\text { HRP-II }]+[\mathrm{P}-670]=[\mathrm{HRP}]_{\text {tot }}} \\
{[\mathrm{RH}]+\left[\mathrm{R}^{\bullet}\right]-\left[\mathrm{O}_{2}\right]+\left[\mathrm{P}_{1}\right]=\mathrm{const}}
\end{gathered}
$$

The first set of dependent substances and the conservation relation are obvious: they involve all of the enzyme species. The second set can only be determined from the stoichiometric matrix.

For the enzyme species the conservation coefficients are

$$
(-1)^{i} M_{i, j}
$$

where $i$ is the number of rows in any column $j$ containing nonzero minors and $M_{i, j}$ is the corresponding minor. For the species in the second conservation relation the coefficients are

$$
(-1)^{j} M_{i, j}
$$

where $j$ is the number of columns in any row $i$ containing nonzero minors.

4.2. Steady State Assumption: Analytical Approach. HRP-II is the predominant catalytic enzyme form in the steady state of IAA oxidation at neutral $\mathrm{pH}^{5}{ }^{5}$ The steady state of HRPII, and presumably all other intermediates, was reached in about $2 \mathrm{~min}$ and maintained for approximately $60 \mathrm{~min}$. All the experimental data used in this section correspond to the conditions $[\mathrm{IAA}]=50 \mu \mathrm{M},[\mathrm{HRP}]=1 \mu \mathrm{M}, \mathrm{pH} 7.4,{ }^{5}$ and time $t=2 \mathrm{~min}$ after the reaction initiation. 
Ten of 12 substances are independent (section 4.1), for example, all substances except $\mathrm{HRP}$ and $\mathrm{P}_{1}$, and they are described by the equations

$\frac{\mathrm{d}[\mathrm{HRP}-\mathrm{I}]}{\mathrm{d} t}=k_{1}[\mathrm{HRP}][\mathrm{ROOH}]-k_{2}[\mathrm{HRP}-\mathrm{I}][\mathrm{RH}]-$

$k_{5}[\mathrm{HRP}-\mathrm{I}][\mathrm{ROOH}](1)$

$\frac{\mathrm{d}[\mathrm{HRP}-\mathrm{II}]}{\mathrm{d} t}=k_{2}[\mathrm{HRP}-\mathrm{I}][\mathrm{RH}]-k_{3}[\mathrm{HRP}-\mathrm{II}][\mathrm{RH}]-$

$k_{4}[$ HRP-II] $(2)$

$$
\frac{\mathrm{d}[\mathrm{P}-670]}{\mathrm{d} t}=k_{5}[\mathrm{HRP}-\mathrm{I}][\mathrm{ROOH}]
$$

$$
\begin{array}{r}
\frac{\mathrm{d}[\mathrm{RH}]}{\mathrm{d} t}=-k_{2}[\mathrm{HRP}-\mathrm{I}][\mathrm{RH}]-k_{3}[\mathrm{HRP}-\mathrm{II}][\mathrm{RH}]- \\
k_{7}\left[\mathrm{ROO}^{\circ}\right][\mathrm{RH}]
\end{array}
$$

$$
\begin{aligned}
& \frac{\mathrm{d}\left[\mathrm{R}^{\bullet}\right]}{\mathrm{d} t}=k_{2}[\mathrm{HRP}-\mathrm{I}][\mathrm{RH}]+k_{3}[\mathrm{HRP}-\mathrm{II}][\mathrm{RH}]- \\
& k_{6}\left[\mathrm{O}_{2}\right]\left[\mathrm{R}^{\bullet}\right]+k_{7}\left[\mathrm{ROO}^{\bullet}\right][\mathrm{RH}]-k_{8}\left[\mathrm{R}^{\bullet}\right]
\end{aligned}
$$

$$
\frac{\mathrm{d}\left[\mathrm{ROO}^{\circ}\right]}{\mathrm{d} t}=k_{6}\left[\mathrm{O}_{2}\right]\left[\mathrm{R}^{\bullet}\right]-k_{7}\left[\mathrm{ROO}^{\circ}\right][\mathrm{RH}]-k_{9}\left[\mathrm{ROO}^{\bullet}\right]
$$

$$
\begin{array}{r}
\frac{\mathrm{d}[\mathrm{ROOH}]}{\mathrm{d} t}=-k_{1}[\mathrm{HRP}][\mathrm{ROOH}]-k_{5}[\mathrm{HRP}-\mathrm{I}][\mathrm{ROOH}]+ \\
k_{7}\left[\mathrm{ROO}^{\circ}\right][\mathrm{RH}]-k_{10}[\mathrm{ROOH}]
\end{array}
$$$$
\frac{\mathrm{d}\left[\mathrm{O}_{2}\right]}{\mathrm{d} t}=-k_{6}\left[\mathrm{O}_{2}\right]\left[\mathrm{R}^{\bullet}\right]
$$$$
\frac{\mathrm{d}\left[\mathrm{P}_{2}\right]}{\mathrm{d} t}=k_{9}\left[\mathrm{ROO}^{\circ}\right]
$$$$
\frac{\mathrm{d}\left[\mathrm{P}_{3}\right]}{\mathrm{d} t}=k_{10}[\mathrm{ROOH}]
$$

The concentrations of intermediates (HRP, HRP-I, HRP-II, $\mathrm{R}^{\bullet}, \mathrm{ROO}^{\bullet}$, and $\mathrm{ROOH}$ ) are constant during the time of the steady state. Therefore, their derivatives are equal to zero.

Equations 1, 2, and 7 can be simplified using the following assumptions. For the beginning of the steady state the following inequality is true: $k_{3}[\mathrm{RH}] \gg k_{4}$. Therefore, the term $k_{4}[\mathrm{HRP}-$ II] can be neglected in eq 2. Moreover, during the oxidation of $50 \mu \mathrm{M}$ of IAA only about $0.5 \mu \mathrm{M}$ of P-670 is formed. We can conclude from this that $k_{5}[\mathrm{ROOH}] \ll k_{2}[\mathrm{RH}]$ and neglect the term $k_{5}[\mathrm{HRP}-\mathrm{I}][\mathrm{ROOH}]$ in eqs 1 and 7 . Using the above assumptions the steady state equations for intermediates become

$$
\begin{aligned}
& 0=k_{1}[\mathrm{HRP}][\mathrm{ROOH}]-k_{2}[\mathrm{HRP}-\mathrm{I}][\mathrm{RH}] \\
& 0=k_{2}[\mathrm{HRP}-\mathrm{I}][\mathrm{RH}]-k_{3}[\mathrm{HRP}-\mathrm{II}][\mathrm{RH}]
\end{aligned}
$$

$$
\begin{array}{r}
0=k_{2}[\mathrm{HRP}-\mathrm{I}][\mathrm{RH}]+k_{3}[\mathrm{HRP}-\mathrm{II}][\mathrm{RH}]-k_{6}\left[\mathrm{O}_{2}\right]\left[\mathrm{R}^{\bullet}\right]+ \\
k_{7}\left[\mathrm{ROO}^{\circ}\right][\mathrm{RH}]-k_{8}\left[\mathrm{R}^{\bullet}\right]
\end{array}
$$

$$
\begin{gathered}
0=k_{6}\left[\mathrm{O}_{2}\right]\left[\mathrm{R}^{\bullet}\right]+k_{7}\left[\mathrm{ROO}^{\bullet}\right][\mathrm{RH}]-k_{9}\left[\mathrm{ROO}^{\bullet}\right] \\
0=-k_{1}[\mathrm{HRP}][\mathrm{ROOH}]+k_{7}\left[\mathrm{ROO}^{\bullet}\right][\mathrm{RH}]-k_{10}[\mathrm{ROOH}]
\end{gathered}
$$

Equations 3, 4, and 8 describing the kinetics of P-670, RH, and $\mathrm{O}_{2}$ (product and substrates rather than intermediates) can also be used in the steady state analysis.

The kinetics of P-670 formation was determined. ${ }^{5} d[\mathrm{P}-670] /$ $\mathrm{d} t$ was determined from a tangent to the kinetic curve of [P-670] $v s t$ at time $t=2 \mathrm{~min}$. At constant $t$ the left side of eq 3 is a constant and the equation becomes

$$
0=k_{5}[\mathrm{HRP}-\mathrm{I}][\mathrm{ROOH}]-\frac{\mathrm{d}[\mathrm{P}-670]}{\mathrm{d} t}
$$

We found that the kinetic traces of $\mathrm{RH}$ consumption are single exponentials ${ }^{5}$ with $k_{\mathrm{obs}}=6.8 \times 10^{-4} \mathrm{~s}^{-1}$ :

$$
[\mathrm{RH}]=[\mathrm{RH}]_{\mathrm{in}} \mathrm{e}^{-k_{\mathrm{obs}} t}
$$

Equation 4 can be integrated in the steady state:

$$
[\mathrm{RH}]=[\mathrm{RH}]_{\mathrm{in}} \mathrm{e}^{-\left(k_{2}[\mathrm{HRP}-\mathrm{I}]+k_{3}[\mathrm{HRP}-\mathrm{II}]+k_{7}\left[\mathrm{ROOH}^{*}\right]\right) t}
$$

Using the last two equations and multiplying by $[\mathrm{RH}]$ we have $0=k_{\mathrm{obs}}[\mathrm{RH}]-k_{2}[\mathrm{HRP}-\mathrm{I}][\mathrm{RH}]-k_{3}[\mathrm{HRP}-\mathrm{II}][\mathrm{RH}]-$

$$
k_{7}\left[\mathrm{ROO}^{\circ}\right][\mathrm{RH}]
$$

We also can use the stoichiometric ratio between $\mathrm{RH}$ and $\mathrm{O}_{2}$. By summation of eqs 4 and 15 and division by eq 8 we obtain

$$
0=1+\frac{k_{8}}{k_{6}\left[\mathrm{O}_{2}\right]}-\frac{\mathrm{d}[\mathrm{RH}]}{\mathrm{d}\left[\mathrm{O}_{2}\right]}
$$

where $\mathrm{d}[\mathrm{RH}] / \mathrm{d}\left[\mathrm{O}_{2}\right]$ can be calculated from the kinetic curves $[\mathrm{RH}]$ vs $t$ and $\left[\mathrm{O}_{2}\right]$ vs $t$. $^{5}$

Equations 11-18 can now be solved. There are experimental values for the rate constants $k_{1}-k_{4}, k_{6}$, and $k_{10}$ (Table 1). At the beginning of the steady state $[\mathrm{IAA}]=[\mathrm{IAA}]_{\text {in }}=5 \times 10^{-5}$ $\mathrm{M},\left[\mathrm{O}_{2}\right]=\left[\mathrm{O}_{2}\right]_{\text {in }}=2.5 \times 10^{-4} \mathrm{M}$, and $[\mathrm{P}-670]=0$. Moreover, the following parameters were calculated from the steady state kinetic measurements: ${ }^{5}[\mathrm{HRP}-\mathrm{II}]=9.0 \times 10^{-7} \mathrm{M}, \mathrm{d}[\mathrm{P}-670] / \mathrm{d} t$ $=2.4 \times 10^{-10} \mathrm{M} \mathrm{s}^{-1}$, and $\mathrm{d}[\mathrm{RH}] / \mathrm{d}\left[\mathrm{O}_{2}\right]=1.31$. Therefore, eqs 13-20 contain the following unknowns: the rate constants $k_{5}$ and $k_{7}-k_{9}$ and the concentrations [HRP], [HRP-I], [R ${ }^{\bullet}$, [ROO ${ }^{*}$, and $[\mathrm{ROOH}$. Since the system is nonlinear, it cannot be solved by the methods of linear algebra. However, it is sufficiently simple that it can be processed manually.

By summation of eqs 11, 15, and 17 and twice the value of eq 12 , we get

$$
[\mathrm{ROOH}]=\frac{k_{\mathrm{obs}}-3 k_{3}[\mathrm{HRP}-\mathrm{II}]}{k_{10}}[\mathrm{RH}]
$$

Equation 12 can be solved for [HRP-I]. By summation of eqs 11 and 12 we get

$$
[\mathrm{HRP}]=\frac{k_{3}[\mathrm{HRP}-\mathrm{II}][\mathrm{RH}]}{k_{1}[\mathrm{ROOH}]}
$$

By summation of eqs 13 and 17 we obtain 


$$
\left[\mathrm{R}^{*}\right]=\frac{k_{\text {obs }}}{k_{8}+k_{6}\left[\mathrm{O}_{2}\right]}[\mathrm{RH}]
$$

The value of $k_{5}$ is determined from eq 16 and $k_{8}$ from eq 18 .

We have determined all parameters except $k_{7}, k_{9}$, and [ROO']. These unknowns occur in eqs 13-15 and 17, which form a linearly dependent system of $k_{7}\left[\mathrm{ROO}^{\circ}\right]$ and $k_{9}\left[\mathrm{ROO}^{\circ}\right]$. The number of unknowns exceeds the number of independent equations. Therefore, the only possibility is to determine the ratio $k_{7} / k_{9}$. From eqs $14-16$

$$
\frac{k_{7}}{k_{9}}=\frac{k_{1}[\mathrm{HRP}]+k_{10}}{\left(k_{1}[\mathrm{HRP}]+k_{10}+k_{6}\left[\mathrm{O}_{2}\right]\left[\mathrm{R}^{\bullet}\right] /[\mathrm{ROOH}]\right)[\mathrm{RH}]}
$$

From a spreadsheet the unknown parameters were calculated: $k_{5}=1.41 \times 10^{3} \mathrm{M}^{-1} \mathrm{~s}^{-1}, k_{8}=1.55 \times 10^{4} \mathrm{~s}^{-1}$, and $k_{7} / k_{9}$ $=6.82 \times 10^{3} \mathrm{M}^{-1}$.

4.3. Computer Optimization. The system of differential equations of the reaction rates, the initial concentrations, and computing parameters appear in Table 2. The equations for the rates of $\mathrm{P}_{1}, \mathrm{P}_{2}$, and $\mathrm{P}_{3}$ formation are not included because they are final products and do not influence the overall reaction. Two additional equations were included in the system for the determination of the contribution of enzymatic and nonenzymatic pathways of IAA oxidation (section 5.2).

After we obtained estimates of the unknown rate constants $k_{5}$ and $k_{7}-k_{9}$ using the steady state assumption, we optimized these values by computer simulation (see the Procedures section). We found that if $k_{7}$ was much more than $k_{3}$, the rate constant of the rate-limiting step, then the outcome of the computer simulation did not depend on $k_{7}$ and $k_{9}$ separately but depended on the ratio $k_{7} / k_{9}$. The behavior of the system is the same with respect to $k_{6}$ and $k_{8}$ : if $k_{6}$ is much more than $k_{8}$, then the result of computer simulation does not depend on $k_{6}$ and $k_{8}$ separately but depends on the ratio $k_{6} / k_{8}$. This simplified the problem of optimization. We fixed $k_{7}=1.0 \times 10^{6} \mathrm{M}^{-1}$ $\mathrm{s}^{-1}$ and varied the ratio $k_{7} / k_{9}$ by varying $k_{9}$. The values $k_{5}, k_{8}$, and $k_{7} / k_{9}$ estimated from the steady state assumption were used for the first iteration in computer optimization. Optimal values of the rate constants were $k_{5}=5.7 \times 10^{2} \mathrm{M}^{-1} \mathrm{~s}^{-1}, k_{8}=9.1 \times$ $10^{4} \mathrm{~s}^{-1}, k_{9}=5.62 \mathrm{~s}^{-1}$, and $k_{7} / k_{9}=1.91 \times 10^{5} \mathrm{M}^{-1}$. The values of $k_{5}$ and $k_{8}$ determined by computer analysis are close to those calculated using the steady state assumption, while the ratio $k_{7} /$ $k_{9}$ obtained from computer approach is 1 order of magnitude more than that estimated in the steady state assumption. One of the possible reasons for this discrepancy could be that a steady state concentration of $\mathrm{ROOH}$ is not attained 2 min after reaction initiation (section 4.1).

Figure 2 shows the computer simulation of the kinetic traces of HRP-II, P-670, IAA, and $\mathrm{O}_{2}$ using the rate constants $k_{1}-k_{4}$, $k_{6}$, and $k_{10}$ available from the literature (Table 1) and $k_{5}$ and $k_{7}-k_{9}$ optimized by computer simulation. The deviation was $4.5 \times 10^{-2}$.

After the initial optimization of the unknown rate constants, we carried out a further optimization which involved all rate constants (excluding $k_{6}$ and $k_{7}$ ), because the rate constants obtained experimentally have standard errors associated with them (Table 1). We did not vary $k_{6}$ and $k_{7}$ in this final optimization because the result of the simulation depends on the ratios $k_{6} / k_{8}$ and $k_{7} / k_{9}$ rather than on $k_{6}$ and $k_{7}$. We changed these ratios by varying values of $k_{8}$ and $k_{9}$. The final optimal set of the rate constants is presented in Table 2. For the rate constants $k_{2}-k_{5}$ and $k_{8}-k_{10}$ there are well-recognizable minimums of deviation when the rate constants have their optimal values. In contrast, the deviation does not have a minimum
TABLE 2: Parameters of Computer Simulation

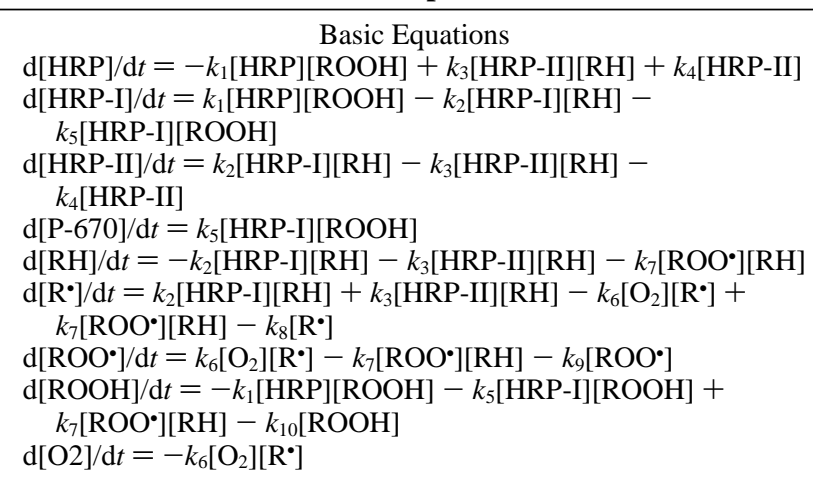

Additional Equations

$\left(\mathrm{d}[\mathrm{RH}]_{\text {oxidized }} / \mathrm{d} t\right)_{\mathrm{enz}}=k_{2}[\mathrm{HRP}-\mathrm{I}][\mathrm{RH}]+k_{3}[\mathrm{HRP}-\mathrm{II}][\mathrm{RH}]$

$\left(\mathrm{d}[\mathrm{RH}]_{\text {oxidized }} / \mathrm{d} t\right)_{\text {nonenz }}=k_{7}\left[\mathrm{ROO}^{*}\right][\mathrm{RH}]$

$\begin{array}{ll}{[\mathrm{HRP}]_{\text {in }}=1 \mu \mathrm{M}} & \text { Initial Concentrations } \\ & {\left[\mathrm{O}_{2] \mathrm{in}}=250 \mu \mathrm{M}\right.} \\ {[\mathrm{RH}]_{\text {in }}=50 \mu \mathrm{M}} & {[\mathrm{ROOH}]_{\text {in }}=0.025 \mu \mathrm{M}^{b}}\end{array}$

Integration Parameters

step size lower limit $=0 \quad$ step size error $=1 \times 10^{-2}$

\section{Optimal Set of Rate Constants}

$\begin{array}{ll}k_{1}=2.0 \times 10^{6} \mathrm{M}^{-1} \mathrm{~s}^{-1} & k_{6}=2.0 \times 10^{8} \mathrm{M}^{-1} \mathrm{~s}^{-1} \\ k_{2}=2.3 \times 10^{3} \mathrm{M}^{-1} \mathrm{~s}^{-1} & k_{7}=1.0 \times 10^{6} \mathrm{M}^{-1} \mathrm{~s}^{-1} \\ k_{3}=2.05 \times 10^{2} \mathrm{M}^{-1} \mathrm{~s}^{-1} & k_{8}=1.8 \times 10^{4} \mathrm{~s}^{-1} \\ k_{4}=1.75 \times 10^{-3} \mathrm{~s}^{-1} & k_{9}=5.62 \mathrm{~s}^{-1} \\ k_{5}=6.2 \times 10^{2} \mathrm{M}^{-1} \mathrm{~s}^{-1} & \mathrm{k}_{10}=1.45 \times 10^{-3} \mathrm{~s}^{-1}\end{array}$

${ }^{a}$ All other initial concentrations are zero. ${ }^{b}$ Except when otherwise stated.
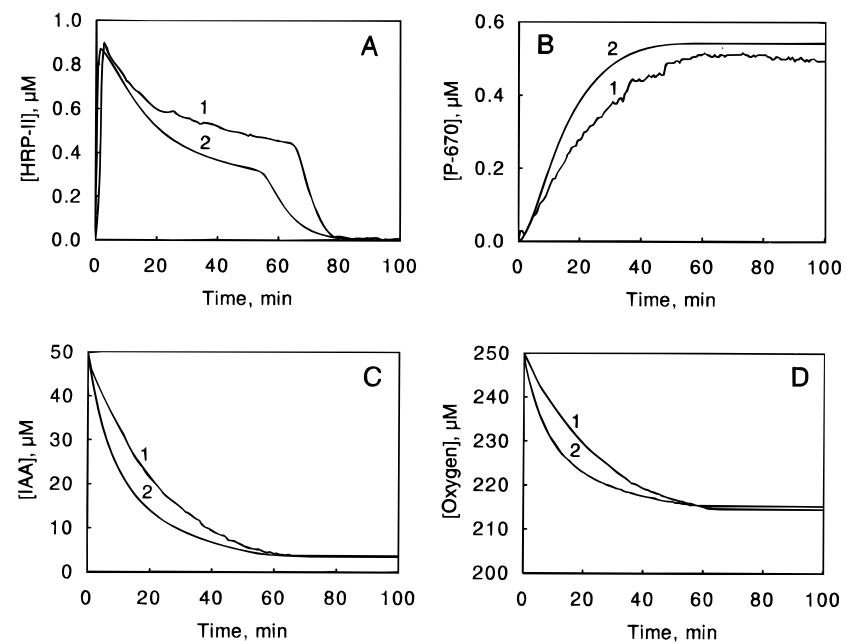

Figure 2. Comparison of (1) experimental ${ }^{5}$ and (2) simulated kinetic traces obtained using optimized values of the previously unknown rate constants: $k_{5}=5.7 \times 10^{2} \mathrm{M}^{-1} \mathrm{~s}^{-1}, k_{8}=9.1 \times 10^{4} \mathrm{~s}^{-1}$, and $k_{9}=5.62$ $\mathrm{s}^{-1}$ obtained assuming $k_{7}=1.0 \times 10^{6} \mathrm{M}^{-1} \mathrm{~s}^{-1}$. Panels $\mathrm{A}-\mathrm{D}$ show concentrations of HRP-II, P-670, IAA, and oxygen as a function of time.

for $k_{1}$ (Figure 3). The deviation decreases with increasing $k_{1}$ up to $k_{1}=2 \times 10^{5} \mathrm{M}^{-1} \mathrm{~s}^{-1}$, beyond which it remains unchanged. The value of $k_{1}=2.0 \times 10^{6} \mathrm{M}^{-1} \mathrm{~s}^{-1}$, available from the literature, ${ }^{2}$ lies on the plateau $D=2.7 \times 10^{-2}$, and we consider this value as an optimal one.

The system is very sensitive to values of the rate constants for chain termination, $k_{8}$ and $k_{9}$. There are critical values of $k_{8}$ and $k_{9}$ which are 3 and 10 times more than the optimal values. If $k_{8}$ and/or $k_{9}$ values exceed the critical ones, then the free radical multiplication factor becomes less than unity and the reaction stops. The system exhibits the same behavior when the rate constants $k_{1}$ or/and $k_{2}$ decrease below critical values. 


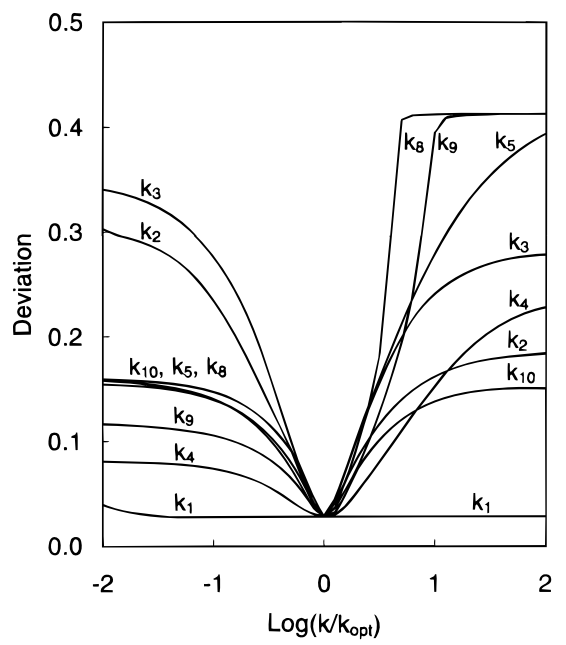

Figure 3. Influence of each rate constant on the deviation between experimental and simulated kinetic traces. The $\log \left(k / k_{\text {opt }}\right)$ scale shows the amount that each rate constant is changed from its optimal value; thus -1 on this scale means the rate constant is one-tenth its optimal value. Each curve is labeled with the single rate constant being changed, while all other rate constants are fixed at optimal values.
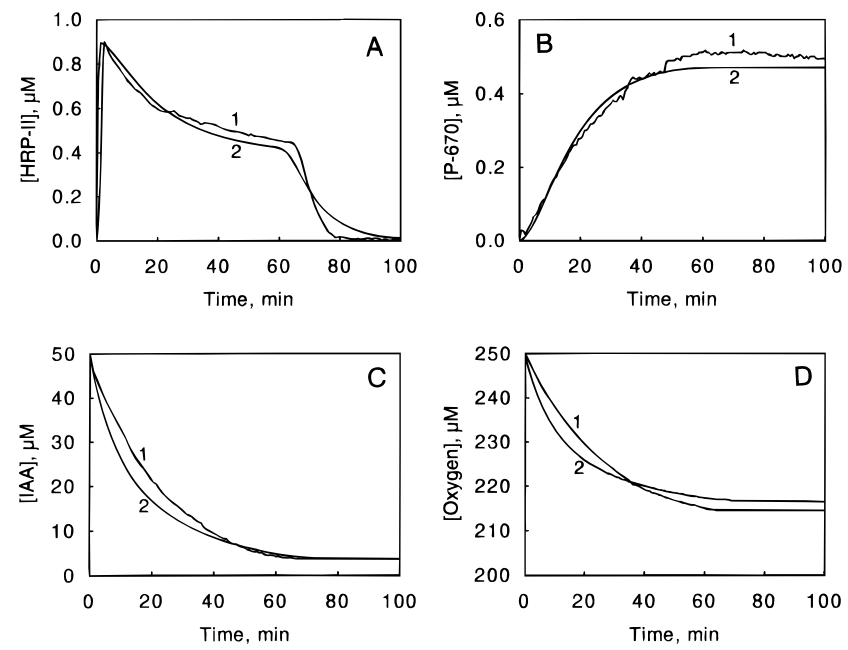

Figure 4. (1) Experimental ${ }^{5}$ and (2) simulated kinetic traces obtained using optimal values for all rate constants including those obtained experimentally (Table 2 ). The panels $\mathrm{A}-\mathrm{D}$ correspond to the same panels in Figure 2. Obvious better fits are obtained in A, HRP-II; and B, P-670.

However, these critical values for $k_{1}$ and $k_{2}$ are about 3 orders of magnitude less than the optimal values. Figure 4 shows experimental kinetic traces and those simulated using the optimal set of the rate constants. Deviation was $2.7 \times 10^{-2}$. By comparison of the data in Tables 1 and 2 it can be seen that the optimization results in little change in rate constants from the experimental values, except for the value of $k_{4}$, which does have a large experimental error. ${ }^{5}$ However, this final fine-tuning of the results did improve the fit to some experimental kinetic traces (compare Figures 2 and 4).

\section{Investigation of the Optimal Model}

5.1. Kinetic Traces of Intermediates. From the model with the optimal set of rate constants we are able to simulate the kinetic traces of intermediates which were not measured experimentally. Figure 5 presents simulated traces of enzyme compounds during IAA oxidation. HRP, HRP-I, and HRP-II achieve a steady state in $1 \mathrm{~min}$. Based on computer simulation of the steady state of the reaction, the ratio [HRP]/[HRP-I]/ [HRP-II] can be crudely expressed as 1/100/1000. The analyti-

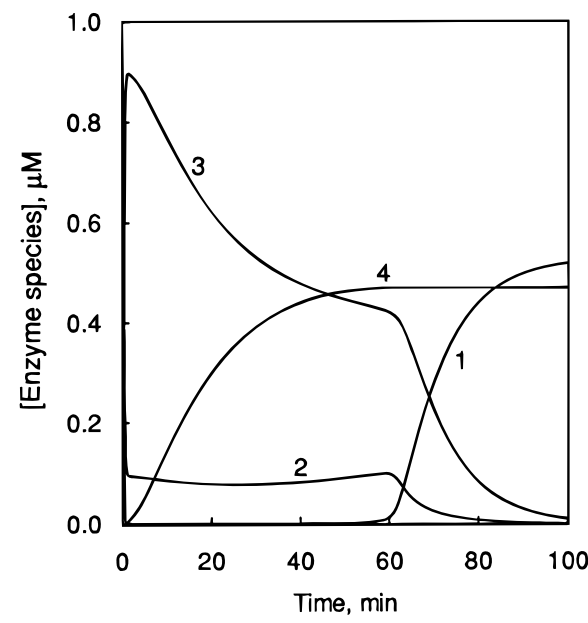

Figure 5. Simulated traces of concentration $v s$ time for different enzyme compounds during IAA oxidation: (1) HRP, (2) HRP-I, (3) HRP-II, and (4) P-670 obtained using optimal values for all rate constants.

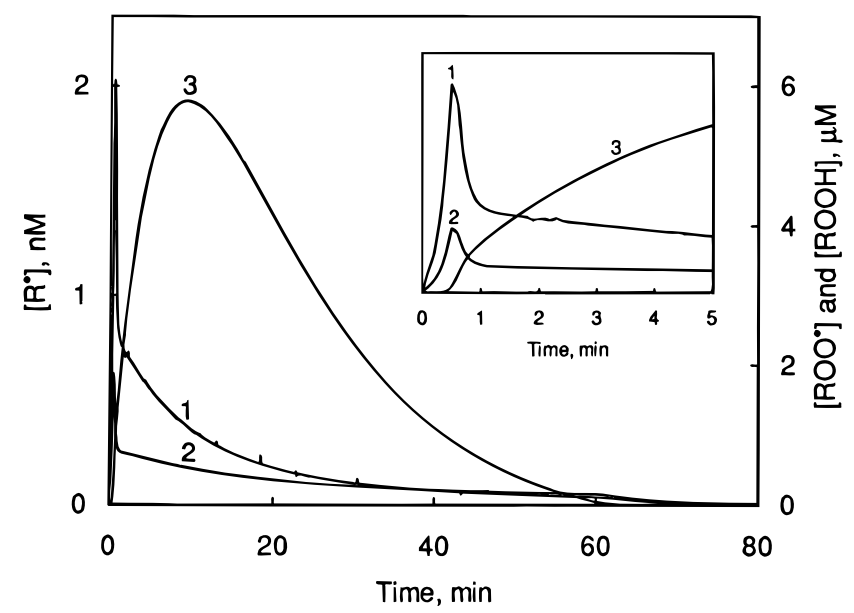

Figure 6. Simulated kinetic traces of (1) R•, (2) ROO*, and (3) ROOH during IAA oxidation using the optimal set of rate constants. The inset shows the first $5 \mathrm{~min}$ of the reaction.

cal investigation of the steady state assumption results in the ratio $1 / 32 / 310$ (eqs 12 and 19-21), which is close to that obtained by computer simulation.

Simulated kinetic traces of $\mathrm{R}^{\circ}, \mathrm{ROO}^{*}$, and $\mathrm{ROOH}$ are shown in Figure 6. The shapes of the $\mathrm{R}^{\bullet}$ and $\mathrm{ROO}^{\bullet}$ traces (curves 1 and 2) are similar. Their concentrations reach maxima of 2 $\mathrm{nM}$ and $2 \mu \mathrm{M}$, respectively, $0.5 \mathrm{~min}$ after reaction initiation and then drop to less then $1 \mathrm{nM}$ and $1 \mu \mathrm{M}$ during the next 0.5 min. These sharp peaks correspond to the pre-steady state of the reaction. The steady state is reached in $1 \mathrm{~min}$. After that, $\left[\mathrm{R}^{\cdot}\right]$ and $\left[\mathrm{ROO}^{*}\right]$ decrease slowly with decreasing [IAA].

We examine the possible pathways of $\mathrm{R}^{\bullet}$ and $\mathrm{ROO}^{\bullet}$ disappearance. One is free radical recombination through dimerization or disproportionation which leads to quadratic rate equations:

$$
\begin{array}{cc}
\mathrm{R}^{\bullet}+\mathrm{R}^{\bullet} \stackrel{k_{8}^{\prime}}{\rightarrow} \text { chain termination } & \left(\mathrm{R}_{8}{ }^{\prime}\right) \\
\mathrm{ROO}^{\bullet}+\mathrm{ROO}^{\bullet} \stackrel{k_{9}^{\prime}}{\rightarrow} \text { chain termination } & \left(\mathrm{R}_{9}{ }^{\prime}\right)
\end{array}
$$

where $k_{8}^{\prime}$ and $k_{9}^{\prime}$ are bimolecular rate constants. The second pathway is free radical deactivation via reaction with nonradical molecules or with the walls of the reaction reservoir. Usually such reactions can be described as pseudo-unimolecular, which 
leads to linear rate equations. A quadratic equation is required only if the concentration of free radicals is sufficiently high.

First we will show that the process of $\mathrm{R}^{\bullet}$ disappearance obeys the linear reaction $\mathrm{R}_{8}$ rather than quadratic $\mathrm{R}_{8}{ }^{\prime}$. From the steady state assumption it was estimated that the experimentally measured values $\mathrm{d}[\mathrm{RH}] / \mathrm{d}\left[\mathrm{O}_{2}\right]=1.31$ and $k_{6}=2 \times 10^{8} \mathrm{M}^{-1}$ $\mathrm{s}^{-1}$ require that $k_{8}=1.55 \times 10^{4} \mathrm{~s}^{-1}($ section 4.2$)$. The quadratic equation can provide such a high rate of free radical disappearance only if

$$
k_{8}^{\prime}=\frac{k_{8}}{\left[\mathrm{R}^{\bullet}\right]}>\frac{1.55 \times 10^{4}}{10^{-9}}=1.55 \times 10^{13} \mathrm{M}^{-1} \mathrm{~s}^{-1}
$$

which is much more than the diffusion-controlled limit. Thus, the quadratic equation is incompatible with the experimental ratio $\mathrm{d}[\mathrm{RH}] / \mathrm{d}\left[\mathrm{O}_{2}\right]=1.31$. We checked this result by computer simulation in which we replaced the linear equation $\mathrm{R}_{8}$ by the quadratic one $\mathrm{R}_{8}{ }^{\prime}$. Our previous conclusion was confirmed: the ratio $\mathrm{d}[\mathrm{RH}] / \mathrm{d}\left[\mathrm{O}_{2}\right]=1.31$ is satisfied only if $k_{8}^{\prime}>10^{13} \mathrm{M}^{-1}$ $\mathrm{s}^{-1}$.

With regard to reaction $\mathrm{R}_{9}{ }^{\prime}$, it is impossible to prove that a quadratic equation is not appropriate because the rate constant $k_{7}$ is not known. Therefore, we used computer simulation with reaction $\mathrm{R}_{9}{ }^{\prime}$ instead of $\mathrm{R}_{9}$ to check the quality of the fit. The best fit in this case was too far from experimental results $(D=$ $5.9 \times 10^{-1}$ compared to $2.7 \times 10^{-2}$ for the optimal model). Therefore, we believe that linear reactions $\mathrm{R}_{8}$ and $\mathrm{R}_{9}$ rather than quadratic reactions $\mathrm{R}_{8}{ }^{\prime}$ and $\mathrm{R}_{9}{ }^{\prime}$ are responsible for disappearance of the free radicals $\mathrm{R}^{\bullet}$ and $\mathrm{ROO}^{\bullet}$.

$\mathrm{ROOH}$ formation has a $0.5 \mathrm{~min}$ lag period and reaches its maximum value of $6 \mu \mathrm{M} 10 \mathrm{~min}$ after reaction initiation (Figure 6, curve 3). In contrast to other intermediates (HRP, HRP-I, HRP-II, R`, and ROO`), ROOH does not achieve its steady state in $1 \mathrm{~min}$. The slow attainment of the steady state occurs because the relaxation time, $\tau$, of ROOH is determined by the slow reactions of $\mathrm{ROOH}$ disappearance, $\mathrm{R}_{1}, \mathrm{R}_{5}$, and $\mathrm{R}_{10}$ :

$$
\tau=\left(k_{1}[\mathrm{HRP}]+k_{5}[\mathrm{HRP}-\mathrm{I}]+k_{10}\right)^{-1} \approx 4 \min
$$

Therefore, the concentration of $\mathrm{ROOH}$ reaches its maximum value only in $t=2.5 \times \tau=10 \mathrm{~min}$ after reaction initiation. Strictly speaking, the system reaches the steady state when all the intermediates reach the steady state, that is, in $10 \mathrm{~min}$. In our consideration of the steady state we assumed that the steady state is reached in $2 \mathrm{~min}$. We believe that some minor discrepancies between the results of the steady state assumption and computer simulation can arise from the result that $\mathrm{ROOH}$ does not reach the steady state in 2 min, as we considered.

We believe that experimental measurements of $[\mathrm{ROOH}]$ as a function of time can be made to examine the validity of the kinetic trace of $\mathrm{ROOH}$ predicted by the model. Nakajima and Yamazaki suggested an indirect way to measure the concentration of ROOH during the IAA oxidation. ${ }^{2}$ They used ascorbate to induce a lag period in IAA oxidation. They believed that the critical concentration of ascorbate which abruptly increased the lag time is equal to the concentration of ROOH. It was bright idea. However the mechanism of the effect of ascorbate on IAA oxidation is not completely clear. Ascorbate is known to be an effective free radical scavenger ${ }^{24}$ and at the same time a substrate for HRP-I and HRP-II. Therefore, ascorbate could inhibit IAA oxidation either by (1) free radical scavenging or by (2) acting as a competitive substrate. In the first case there is no direct connection between ascorbate and hydroperoxide concentrations. In the second case it needs to be proved that the critical concentration of ascorbate is equal to the concentration of ROOH. It should be noted that many phenolic inhibitors

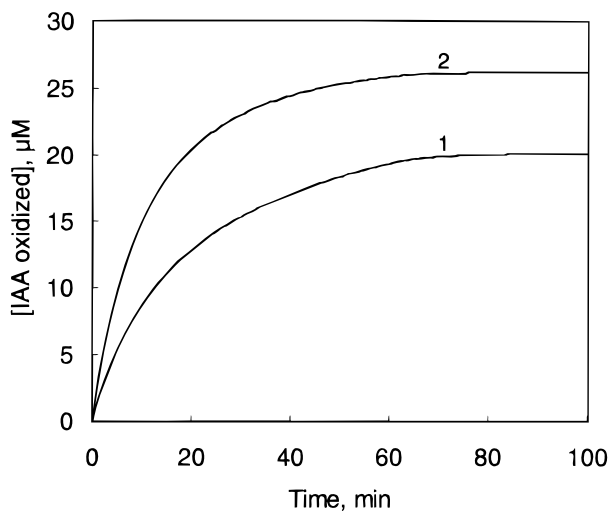

Figure 7. Simulated contributions of (1) enzymatic and (2) and nonenzymatic pathways in IAA oxidation obtained using the optimal set of rate constants.

of IAA oxidation exhibit the same critical behavior with respect to IAA oxidation as ascorbate. ${ }^{18}$ The mechanism of this inhibition is still unknown, and we plan to investigate it.

5.2. Nonenzymatic Oxidation of IAA. In our previous paper we estimated a lower limit of $1 / 3$ for the nonenzymatic contribution to IAA oxidation. That estimate was based upon experimentally measured rate constants and the upper limit of HRP-II concentration: $k_{\text {obs }}=(6.8 \pm 0.4) \times 10^{4} \mathrm{~s}^{-1}, k_{3}=(2.3$ $\pm 0.2) \times 10^{2} \mathrm{M}^{-1} \mathrm{~s}^{-1}$, and $[\mathrm{HRP}-\mathrm{II}] \leq[\mathrm{HRP}]_{\text {in }}=1 \mu \mathrm{M}$. Using a more precise value for the average concentration of HRP-II, $[\mathrm{HRP}-\mathrm{II}]_{\mathrm{av}}=0.58 \mu \mathrm{M}$ (section 2.1), and the same approach as in ref 5, we calculate the experimental contribution of nonenzymatic reactions in IAA oxidation as

$$
C_{\text {nonenz }}^{\exp }=0.62 \pm 0.27
$$

Using the two additional equations listed in Table 2, we simulated the kinetic traces of IAA oxidized by both enzymatic and nonenzymatic reactions (Figure 7). The simulated contribution of the nonenzymatic pathway is

$$
C_{\text {nonenz }}^{\text {sim }}=0.57
$$

The experimental and simulated contributions are very close to each other. This confirms that the suggested model is adequate.

5.3. Initiation Step of IAA Oxidation. Identification of the initiation step of peroxidase-catalyzed IAA oxidation remains one of the unsolved problems in this system. Two possible ways of reaction initiation were suggested: the peroxidase and oxidase pathways. ${ }^{2,3}$ The peroxidase pathway requires the presence of hydroperoxide traces in IAA. Neither the sublimation nor recrystallization of IAA influences the reaction initiation, ${ }^{4,17}$ which means either that oxidase pathway is the initiation step or that the reaction can be initiated by a very low concentration of organic hydroperoxide formed or remaining after purification of IAA. We were not able to model the oxidase pathway as the initiation step because the relevant rate constants are not available. Therefore, we modeled the initiation of the reaction by the peroxidase pathway, which is the main pathway once the steady state is established. We simulated the effect of initial hydroperoxide concentration, $[\mathrm{ROOH}]_{\mathrm{in}}$, on the rate of reaction initiation. We found that a decrease of $[\mathrm{ROOH}]_{\text {in }}$ resulted in a short delay of the reaction initiation, which is followed by kinetic traces of HRP-II (Figure 8). The delay is proportional to the negative logarithm of $[\mathrm{ROOH}]_{\mathrm{in}}$. The dependence of the delay on $[\mathrm{ROOH}]_{\text {in }}$ is so weak because in the pre-steady state (initiation step) the production of $\mathrm{ROOH}$ by the branching chain reaction obeys the exponential law 


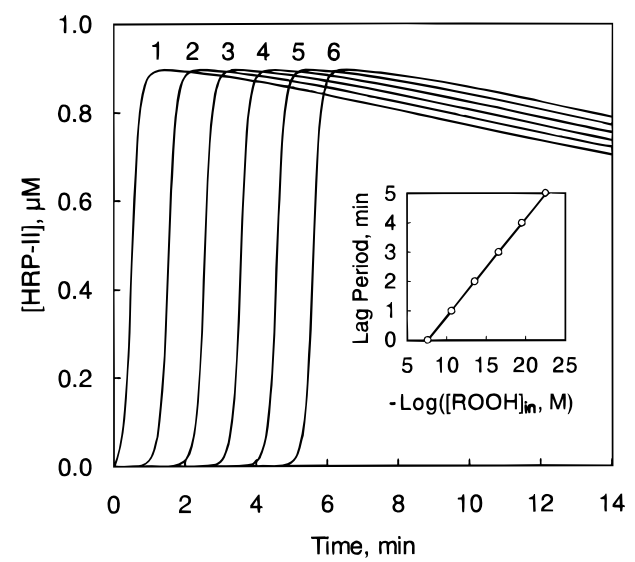

Figure 8. Computer simulation of the effect of $[\mathrm{ROOH}]_{\text {in }}$ on the kinetic traces of HRP-II showing increasing lag period with decreasing $[\mathrm{ROOH}]_{\text {in }}$. The initial concentrations of ROOH are (1) $2.5 \times 10^{-8}$, (2) $2.5 \times 10^{-11}$, (3) $2.5 \times 10^{-14}$, (4) $2.5 \times 10^{-17}$, (5) $2.5 \times 10^{-20}$, and (6) $2.5 \times 10^{-23} \mathrm{M}$. Optimal values for all rate constants are used. The inset shows reaction lag period as a function of the negative logarithm of $[\mathrm{ROOH}]_{\text {in }}$.

$$
[\mathrm{ROOH}]=[\mathrm{ROOH}]_{\mathrm{in}} \mathrm{e}^{k t}
$$

We also investigated the influence of $k_{7}$ on the lag period caused by changing $[\mathrm{ROOH}]_{\mathrm{in}}$. The value of $k_{7}$ had not previously been optimized because for $k_{7} \gg k_{3}$ the simulation results for the reaction beyond the lag period were dependent upon the ratio $k_{7} / k_{9}$ (section 4.3). The result of simulation showed that the lag period is almost independent of the value of $k_{7}$ in the range between $10^{5}$ and $10^{7} \mathrm{M}^{-1} \mathrm{~s}^{-1}$; the value of $k_{7}$ used in the optimal model is within this range.

Although IAA purification had no apparent influence on reaction initiation, ${ }^{4,17}$ it is a negative result which does not disprove reaction initiation by hydroperoxide. Hydroperoxide is always formed from IAA in the presence of oxygen, and even a very small $[\mathrm{ROOH}]$ would be enough for reaction initiation. Indeed, according to our modeling, the decrease of $[\mathrm{ROOH}]_{\text {in }}$ by a factor $10^{15}$ to $[\mathrm{ROOH}]_{\text {in }}=2.5 \times 10^{-23} \mathrm{M}$ (which corresponds to one molecule of $\mathrm{ROOH}$ per liter of solution) results in only a $5 \mathrm{~min}$ delay in reaction initiation.

\section{Concluding Remarks}

The model suggested and developed adequately describes all the available experimental results and can be used for planning of further experimental work and for further development of the model itself. Oscillations have been observed in the HRPIAA system at acidic $\mathrm{pH} .{ }^{25}$ At neutral $\mathrm{pH}$ the oxidation of IAA proceeds exclusively through the peroxidase pathway. For the most intensively studied HRP oscillating system, in which $\mathrm{NADH}$ is the reductant, involvement of both the peroxidase and oxidase pathways is required. ${ }^{6}$ Therefore, it may not be possible to construct an oscillator for the HRP-IAA system at neutral $\mathrm{pH}$.

The initiation step of IAA oxidation can be accounted for by infinitesimally small traces of hydroperoxide which are ampli- fied exponentially by a branching chain reaction. Computer simulation predicts that $[\mathrm{ROOH}]$ reaches its steady state value $10 \mathrm{~min}$ after reaction initiation, whereas all other intermediates reach a steady state in $1 \mathrm{~min}$. Experimental examination of the 10 min delay to reach a steady state in $[\mathrm{ROOH}]$ is required. Such an examination requires development of reliable techniques for measurement of $[\mathrm{ROOH}]$. Since $\mathrm{ROOH}$ is apparently responsible for light emission during IAA oxidation, ${ }^{11}$ the comparison of $\mathrm{ROOH}$ kinetic data with those of chemiluminescence would be of interest.

The model presented here predicts the value of a new investigation of the inhibition of IAA oxidation by the donors of electrons such as phenols. There are two main hypotheses for the mechanism of inhibition: the inhibitor is a free radical scavenger and/or a competitive substrate.

Acknowledgment. Research was supported by the Natural Sciences and Engineering Research Council of Canada.

\section{References and Notes}

(1) Abbreviations used were IAA, RH, indole-3-acetic acid; ROOH, hydroperoxide derived from IAA; NADH, reduced nicotinamide adenine dinucleotide; HRP, HRP-I, HRP-II, and HRP-III are native form, compound I, compound II, and compound III of horseradish peroxidase; P-670, inactive verdohemoprotein; $\mathrm{P}_{1}, \mathrm{P}_{2}$, and $\mathrm{P}_{3}$, unidentified products of $\mathrm{R}^{\bullet}, \mathrm{ROO}{ }^{*}$, and ROOH destruction; subscripts in, av, and tot mean initial, average, and total.

(2) Nakajima, R.; Yamazaki, I. J. Biol. Chem. 1979, 254, 872.

(3) Smith, A. M.; Morrison, W. L.; Milham P. J. Biochemistry 1982, $21,4414$.

(4) Metodiewa, D.; de Melo, M. P.; Escobar, J. A.; Cilento, G.; Dunford, H. B. Arch. Biochem. Biophys. 1992, 296, 27.

(5) Krylov, S. N.; Dunford, H. B. Biophys. Chem., in press.

(6) (a) Olson, D. L.; Scheeline, A. J. Phys. Chem. 1995, 99, 1204. (b) Olson, D. L.; Scheeline, A. J. Phys. Chem. 1995, 99, 1212. (c) Olson, D. L.; Williksen, E. P.; Scheeline, A. J. Am. Chem. Soc. 1995, 117, 2.

(7) Odajima, T.; Yamazaki, I. Biochim. Biophys. Acta 1970, 206, 71

(8) Cilento, G.; Adam, W. Photochem. Photobiol. 1988, 48, 361.

(9) Krylov, S. N.; Aguda, B. D.; Ljubimova, M. L. Biophys. Chem. 1995, 55,213

(10) Krylov, S. N.; Lazarev, V. V.; Rubin, L. B. Dokl. Biophys. 1990, $310,28$.

(11) de Melo, M. P.; Escobar, J. A.; Metodiewa, D.; Dunford, H. B.; Cilento, G. Arch. Biochem. Biophys. 1992, 296, 34.

(12) Krylov, S. N.; Chebotareva, A. B. FEBS Lett. 1993, 324, 6

(13) Dorffling, K. Das Hormonsystem der Pflanzen; Georg Thieme Verlag: New York, 1982.

(14) Kobayashi, S.; Sugioka, K.; Nakano, H.; Nakano, M.; Tero-Kubota, S. Biochemistry 1984, 23, 4589.

(15) Nakajima, R.; Yamazaki, I. J. Biol. Chem. 1980, 255, 2067.

(16) Acosta, M.; Arnao, M. B.; Del Rio, J. A.; Garcia-Canovas, F. Biochim. Biophys. Acta 1989, 996, 7.

(17) Dunford, H. B. Quim. Nova 1993, 16, 350.

(18) Krylov, S. N.; Krylova, S. M.; Chebotarev, I. G.; Chebotareva, A. B. Phytochemistry 1994, 36, 263.

(19) Yokota, K.; Yamazaki, I. Biochemistry 1977, 16, 1913.

(20) Robinson, J.; Cooper, J. M. Anal. Biochem. 1970, 33, 390.

(21) Press, W. H.; Flannery, B. P.; Tenkolsky, S. A.; Vetterling, W. T. Numerical Recipes. The Art of Scientific Computing; Cambridge University Press: Cambridge, 1992.

(22) Candeias, L. P.; Folkes, L. K.; Dennis, M. F.; Patel, K. B.; Everett,

S. A.; Stratford, M. R. L.; Wardman, P. J. Phys. Chem. 1994, 98, 10131 (23) Clarke, B. L.; Jiang, W. J. Chem. Phys. 1993, 99, 4464.

(24) Wu, T. W.; Zeng, L. H.; Wu, J.; Fung, K. P. Life Sci. 1993, 53, PL213.

(25) Degn, H. Biochim. Biophys. Acta 1969, 180, 271.

JP9522270 